University of Louisville

ThinkIR: The University of Louisville's Institutional Repository

$5-2018$

\title{
The effects of a physical activity program called "minds-in- motion-the maze" on balance and motor skills in middle school aged students.
}

\author{
Liliana Vargas \\ University of Louisville
}

Follow this and additional works at: https://ir.library.louisville.edu/etd

Part of the Curriculum and Instruction Commons, Curriculum and Social Inquiry Commons, Elementary and Middle and Secondary Education Administration Commons, Exercise Science Commons, Health and Physical Education Commons, Motor Control Commons, and the Other Kinesiology Commons

\section{Recommended Citation}

Vargas, Liliana, "The effects of a physical activity program called "minds-in-motion-the maze" on balance and motor skills in middle school aged students." (2018). Electronic Theses and Dissertations. Paper 2988.

https://doi.org/10.18297/etd/2988

This Master's Thesis is brought to you for free and open access by ThinkIR: The University of Louisville's Institutional Repository. It has been accepted for inclusion in Electronic Theses and Dissertations by an authorized administrator of ThinkIR: The University of Louisville's Institutional Repository. This title appears here courtesy of the author, who has retained all other copyrights. For more information, please contact thinkir@louisville.edu. 
THE EFFECTS OF A PHYSICAL ACTIVITY PROGRAM CALLED "MINDS-INMOTION- THE MAZE" ON BALANCE AND MOTOR SKILLS IN MIDDLE SCHOOL AGED STUDENTS

\author{
By \\ Liliana Vargas \\ B.A., California State University Channel Islands, 2011 \\ M.S., University of Louisville, 2018
A Thesis
Submitted to the Faculty of the
College of Education and Human Development of the University of Louisville in Partial Fulfillment of the Requirements
for the Degree of \\ Master of Science
in Exercise Physiology
}

Department of Health \& Sport Sciences

University of Louisville

Louisville, Kentucky

May 2018 

THE EFFECTS OF A PHYSICAL ACTIVITY PROGRAM CALLED "MINDS-INMOTION- THE MAZE" ON BALANCE AND MOTOR SKILLS IN MIDDLE SCHOOL AGED STUDENTS

\author{
By \\ Liliana Vargas \\ B.A., California State University Channel Islands, 2011 \\ M.S., University of Louisville, 2018
}

A Thesis Approved on

April 16, 2018

By the following Thesis Committee:
Daniela Terson de Paleville, $\mathrm{PhD}$
Thesis Director
Kathleen Carter, $\mathrm{PhD}$
Committee Member
Douglas J. Lorenz, PhD
Committee Member




\section{DEDICATION}

This thesis is dedicated to Mr. Martin. Thank you for your dedication and help

throughout the entire project. Furthermore, I would like to dedicate this thesis to my Minds in Motion family: Ms. Candace, Ms. Carol, Ms. Melanie, Ms. Diane, and Mr. Greg for teaching me everything I know about Minds in Motion.

Thank you all. 


\section{ACKNOWLEDGMENTS}

I would like to acknowledge the teachers, administrators, parents, and students of Plainfield Community Middle School who made Minds in Motion-MAZE a possibility. 


\section{ABSTRACT \\ THE EFFECTS OF A PHYSICAL ACTIVITY PROGRAM CALLED "MINDS-IN- MOTION- THE MAZE" ON BALANCE AND MOTOR SKILLS IN MIDDLE SCHOOL AGED STUDENTS}

Liliana Vargas

April 16, 2018

Competing time demands in the curriculum have left physical education as a low priority among schools. Consequently, school aged children are not meeting the recommended 150 mins/wk of physical activity. We studied the effects of Minds in Motion-MAZE on middle school aged $(n=74)$ children's balance and motor skills. Minds in Motion-MAZE is a low cost physical activity program designed to improve balance and motor control. Participants participated in Minds in MotionMAZE for 15 minutes during the $7^{\text {th }}$ period. A multivariate test did not show a statistical significance of participating in Minds in Motion-MAZE and improved balance and motor skills. Further analysis is required to assess the effect of Minds in Motion-MAZE as a viable alternative to a lack of physical education in the curriculum. 
TABLE OF CONTENTS

PAGE

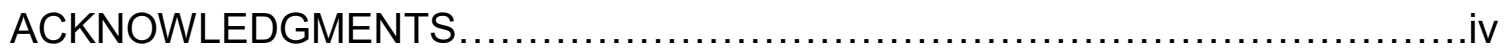

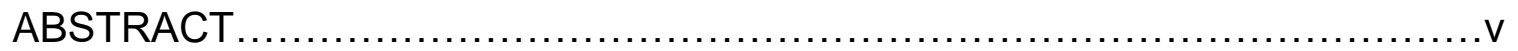

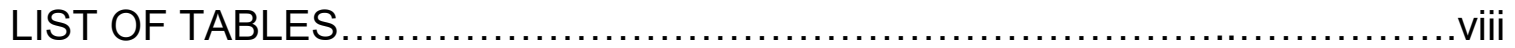

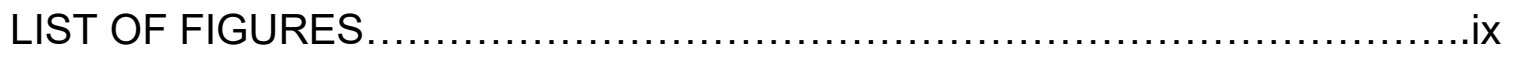

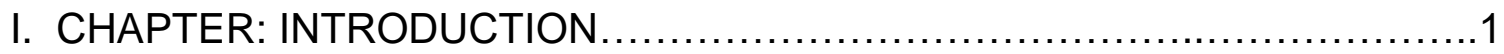

A: The Vestibular System: An Introduction................................4

B: Peripheral Vestibular System.........................................

B.1: Semicircular Canals: Angular Acceleration...........................5

B.2: Utricle \& Saccule: Linear Acceleration..................................

B.3: Cochlea: Auditory System.......................................

C: The Vestibular System \& Visual System ............................... 8

C.1: Vestibulo-Ocular Reflex (VOR): Gaze Stability ........................ 8

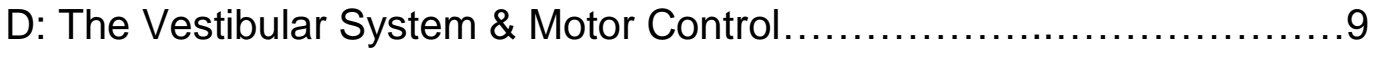

D.1: The Vestibular System \& Motor Control: Cerebellum..................10

E: The Vestibular System \& Somatosensory Interactions..................11

E.1: The Vestibular System \& Somatosensory Interactions:

Proprioception.....................................................

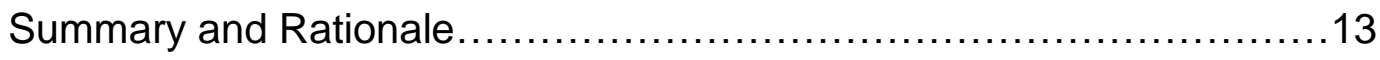

Aims and hypotheses................................................ 
II. METHODS AND MATERIALS ................................................. 14

A. Ethical Approval for Human Studies...................................14

B. Experimental Procedures...........................................14

1. Facilities/Resources..................................................14

2. Participants ..............................................................

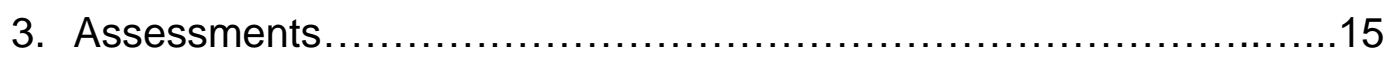

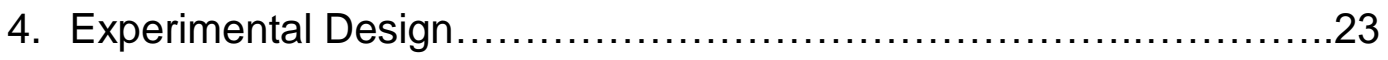

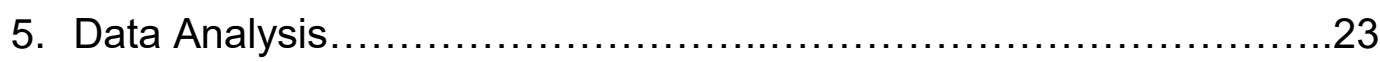

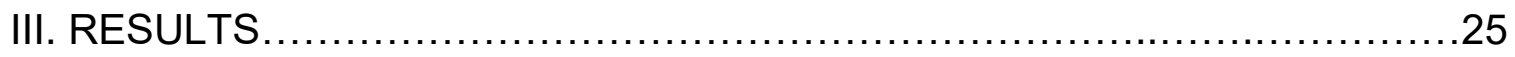

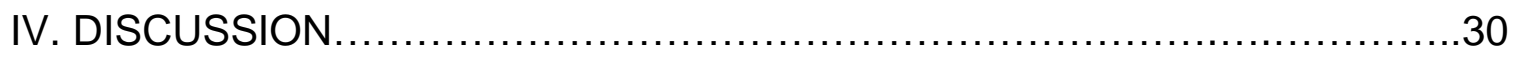

V. SUMMARY AND CONCLUSIONS ...........................................

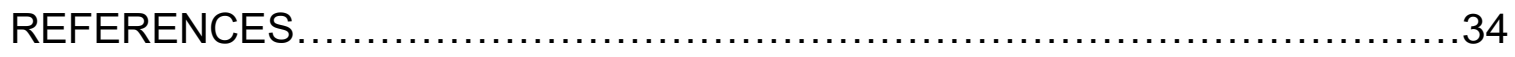

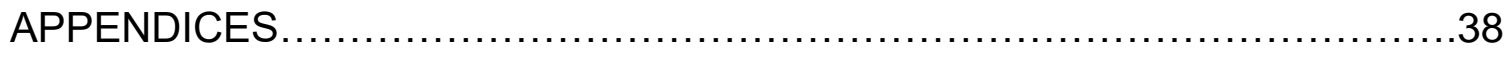

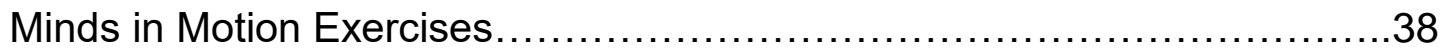

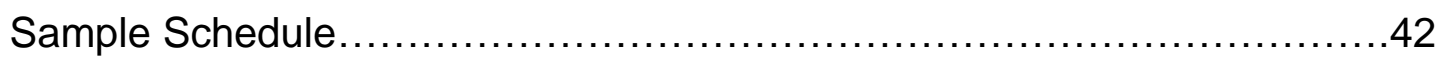

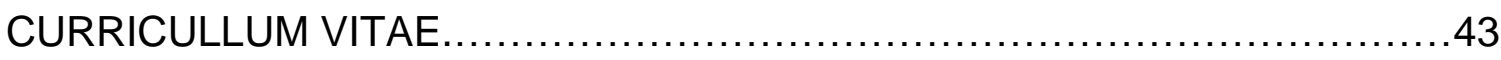




\section{LIST OF TABLES}

TABLE

PAGE

1. Subtest 1: measures fine motor precision ................................. 17

2. Subtest 2: measures fine motor integration ............................17

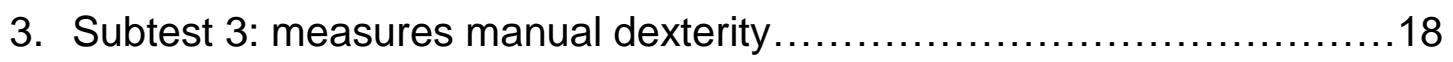

4. Subtest 4: measures bilateral coordination...............................19

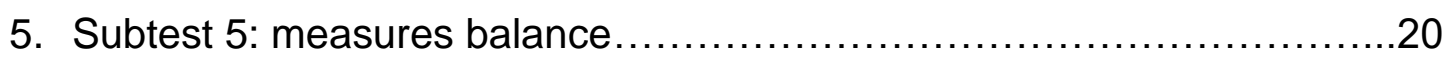

6. Subtest 6: measures running speed and agility .........................21

7. Subtest 7: measures upper-limb coordination ...........................21

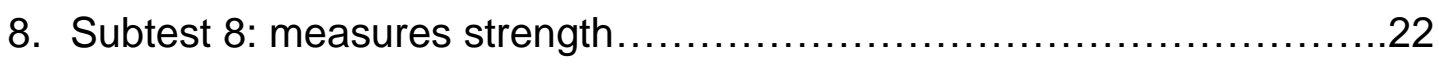

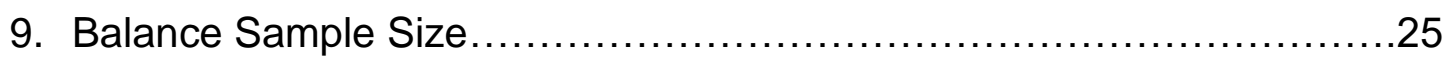

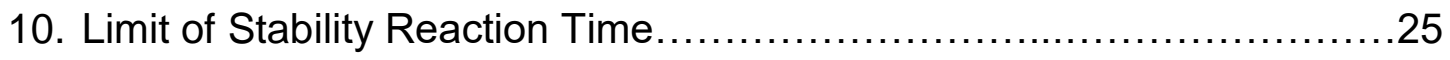

11. Limit of Stability Movement Velocity ....................................26

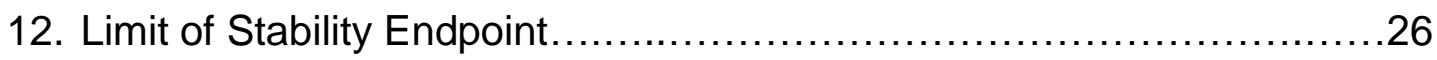

13. Limit of Stability Maximum Excursion....................................27

14. Limit of Stability Directional Control...................................27

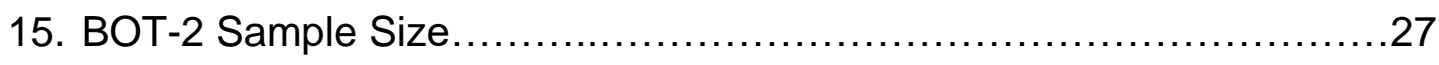

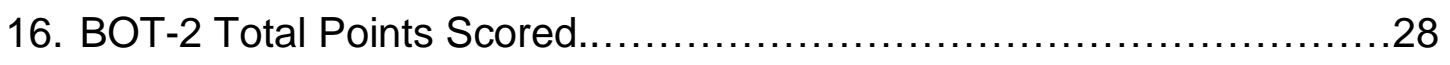

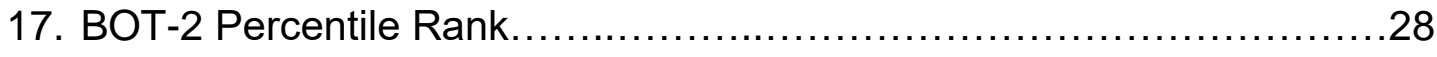




\section{LIST OF FIGURES}

FIGURE $\quad$ PAGE

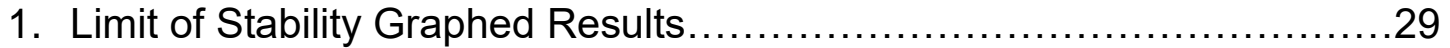




\section{CHAPTER I}

\section{INTRODUCTION}

In 1986 the National Association for Sport and Physical Education (NASPE) identified five major outcomes of physical education as: (1) to pursue a lifetime of healthy physical activity; (2) to learn necessary skills to perform various physical activities; (3) to be physically fit; (4) to regularly participate in physical activity; and (5) to be aware of the benefits of physical activity involvement (as cited in Couturier, Chepko, \& Holt, 2014; referenced in Hastie, 2017). These original outcomes were revised to "physically literate individuals who have the knowledge, skills and confidence to enjoy a lifetime of healthful physical activity" (as cited in Couturier et al., 2014). Yet, despite these recommendations, only 11 states have specified guidelines of ensuring these outcomes are met (Belton, Prior, Wickel, \& Woods, 2017; Hastie, 2017; Donnelly et al., 2017).

It is suggested that children with competent levels of motor skills are more likely to be physically active than children with low motor skill performance (Chen, Hammond-Bennett, \& Hypnar, 2017). Wrotniak, Epstein, Dorn, Jones, \& Kondilis (2006) found motor skill proficiency, measured by using Bruininks- 
Oseretsky Test of Motor Proficiency, to be positively correlated to physical activity and negatively correlated to sedentary behavior among 8 to 10 year olds. Pacheco, Gabbard, Ries, \& Bobbio (2016) found a positive correlation $(p<.001)$ among high academic performance (>75\%) and high total motor proficiency composite scores in 60 boys and 40 girls $(n=100)$ between the ages of 8 to 11 . They further concluded that motor proficiency scores in bilateral coordination tasks had a significant correlation $(\mathrm{p}=.026$ when performing jumping jacks and $\mathrm{p}=.005$ when tapping the foot and finger on opposite sides simultaneously) to academic performance.

Competing time demands in the curriculum have left physical education as a low priority to schools, particularly if the state in which the school resides does not have a law outlining the requirements for physical education and/or recess (Slater, Nicholson, Chriqui, Turner, \& Chaloupka, 2012). Giving physical education a low priority diminishes the likelihood students will achieve the recommended physical activity. One hundred and fifty minutes per week of physical education is the nationally accepted and endorsed recommendation for school-aged children by the National Standards \& Grade-Level Outcomes for K12 physical education (Couturier et al., 2014). Yet, fewer than $20 \%$ of students achieve this recommendation (Policy Position Statement on Physical Education in Schools, 2008; Slater et al., 2012). Studies show students who participate in physically active academic lessons show a $6 \%$ improvement on academic achievement tests compared to a $1 \%$ decrease in performance among students not participating in physically active academic lessons (Donnelly et al., 2017). 
This trend is consistent among middle school and high school students; regardless of physical activity performed indoor or outdoor, the benefits of a physically active break was observed in improved academic performance (Hood, Colabianchi, Terry-McElrath, O'Malley, \& Johnston, 2014). During a typical school day, students have 3 distinct forms of participating in physical activity: (1) physical education, (2) recess, and (3) other unstructured physical activities (Slater et al., 2012). However, the recommended 150 mins/wk of physical activity is rarely met (Haapala et al., 2017).

To asses health and wellness among school aged children and the overall population, the National Health Interview Survey (NHIS) gathers information about various disabilities in the United States and the widespread public health impact (Cohen \& Zammitt, 2018; O'Mara et al., 2017). Since its inception, various revisions have been implemented with the continued effort to promote health and wellness and reduce disabilities. Although recently, balance disorders have begun to plague school aged children (Li et al., 2016). In 2012, the National Institute on Deafness and Other Communication Disorders added a subsection to the NHIS in an effort to record the progress of the new Healthy People 2020 objective. The added component to the NHIS was specifically designed to determine and evaluate the prevalence of children suffering, previously treated for, and/or currently receiving treatment for complaints of vertigo and/or balance. The survey contains questions as follows:

During the past 12 months, has your child been bothered by episodes of any of the following dizziness or balance problems: (1) vertigo, a spinning 
sensation like a carousel ("vertigo"); (2) poor balance, an unsteady or woozy feeling that makes it difficult to stand up or walk ("poor balance");

(3) problems with body or motor coordination or clumsiness ("poor coordination"); (4) frequent falls ("frequent falls"); (5) light-headedness, fainting, or feeling he/she is about to pass out ("light-headedness"); and (6) any other type of balance or dizziness problems ("other dizziness and balance problems").

The authors found that among children aged 3 to 17 years old, $46 \%$ reported poor coordination, 35.1\% reported light-headedness, 30.9\% reported poor balance, vertigo without any other symptoms was reported by $7.2 \%$, and a compilation of vertigo and poor balance was reported by $14.1 \%$. A large portion of the children suffering headaches and/or migraines also suffered from vestibular disorders. Of the children suffering from dizziness and balance problems, $36 \%$ reported being treated by a healthcare professional at some point in their life. Overall, researchers found a significant increase, from $29.9 \%$ to $75 \%$, in children suffering from dizziness and balance.

\section{A: The Vestibular System: An Introduction}

Although primarily for providing the cerebral cortex with sensory information regarding head movement, orientation, and balance, the vestibular system is an intricate sensory system that permits the individual to execute various functions (Fitzpatrick \& Watson, 2015). The vestibular system consists of semicircular canals and otolith organs that provide angular and linear acceleration. The vestibular system receives information for head alignment and 
motor reflexes to maintain balance by using an intricate web of sensory signals regarding spatial and non-spatial surroundings to provide a three-dimensional format. Using visual, auditory, tactile, proprioceptive, motor and interoceptive signals the vestibular system allows for maintained constant awareness of the body in relation to spatial surroundings (Pfeiffer, Serino, \& Blanke, 2014).

\section{B: Peripheral Vestibular System}

The peripheral vestibular system, or the inner ear as it is often referred as, comprises of two labyrinths, a bony labyrinth enclosing the membranous labyrinth, located in the petrous portion of the temporal bone (Santos et al., 2017). The bony labyrinth consists of three semicircular canals openly connected to an enlarged vestibule leading to the cochlea.

\section{B.1: Semicircular Canals: Angular Acceleration}

The semicircular canals comprise of 3 delicately located canals set at approximately $90^{\circ}$ to each other: the anterior, posterior, and horizontal canals provide angular acceleration and sensation for pitch and roll (Iversen \& Rabbitt 2017). When the head moves in the anatomical plane of a canal, a peak excitation is produced within the semicircular canal while the surrounding canals, oriented in the null plane, are dormant (Ifediba, Rajguru, Hullar, \& Rabbitt, 2007). Each semicircular canal is filled with endolymph fluid continuous throughout the labyrinth and enlarges into a crista ampullaris that houses the cupula (Santos et al., 2017). Within the cupula are hair cells that when bent by the inertial movement of the jellylike fluid contained within the cupula, a sensory signal is transmitted from the vestibular nerve to the vestibular portion of the 
vestibulocochlear nerve. Furthermore, the vestibular portion of the vestibulocochlear nerve receives information regarding proprioceptive and visual cues to allow visual fixation while the body is in motion (Seeley, VanPutte, Regan, \& Russo, 2011).

Ifediba, Rajguru, Hullar, \& Rabbitt (2007) questioned the accepted dynamics and biomechanics of the semicircular canals due to the current literature's inability to explain how fluid communicates collectively among the canals as well as its inability to explain the required delicate geometry of the canals in relation to each other. Using histological slides of a 67 -year-old male and 43-year-old female without vestibular issues, a 3-D geometrical model of the semicircular canals and labyrinth was constructed. Various head rotations were used to analyze and mathematically predict endolymph flow and the subsequent effect on the cupula. Taking into account previous reports regarding labyrinth shrinkage or lack thereof, three different 3-D geometrical models were constructed.

Group A didn’t account for shrinkage, Group B accounted for $9.2 \%$ uniform labyrinth shrinkage, while Group C accounted for non-uniform labyrinth shrinkage: $4 \%$ shrinkage in the horizontal canal, $16 \%$ shrinkage in the anterior and posterior canals, $13 \%$ shrinkage of the ampulla, and $33 \%$ shrinkage of the utricle. They found afferent responses weren't maximal in the plane of the afferent input and null in the corresponding planes, but rather as maximal response was elicited in one canal, the corresponding canals continued to display responses but to a lesser extent. Thus concluding, the interpretation of 
afferent responses is due to collective responses of the semicircular canals and not just orthogonal mechanics.

\section{B.2: Utricle \& Saccule: Linear Acceleration}

While the semicircular canals account for angular acceleration, linear acceleration is interpreted by the otolith organs, the utricle and saccule, which are continuous with the semicircular canals in the membranous labyrinth (Santos et al., 2017). The utricle and saccule house the macula containing hair cells that translate mechanical stress to nerve impulses (Seeley et al., 2011). Covering the hair cells is the otolithic membrane, a gelatinous membrane, covered with calcium carbonate crystals called otoconia. When the otoconia are displaced by changes to the gravitational pull, the gelatinous fluid in the otolithic membrane causes mechanical stress in the hair cells that is converted to a neural signal

The utricle houses the macula at the floor to allow for vertical movement interpretation (Santos et al., 2017). The saccule houses the macula on its medial wall which interprets horizontal movement. Due to equivalent structure of the inner ear when hair cells are excited on a particular side, the corresponding hair cells on the opposite side are inhibited allowing for precise identification of head movement.

\section{B.3: Cochlea: Auditory System}

Responsible for transmitting sound waves to neural signals, the cochlea is a spiralized pressurized system within the petrous bone (Ziegler, Wahl, \& Eberhard, 2017). Despite being continuous with the bony labyrinth, part of the membranous labyrinth, and vestibule, the cochlea is not considered part of the 
vestibular system but rather its own system, the auditory system. Together the auditory nerve, which transmits neural activity from the cochlea, and the vestibular nerve make up the vestibulocochlear nerve (Seeley et al., 2011).

\section{C: The Vestibular System \& Visual System}

The visual system perceives object movement, identifies surfaces and edges relative to the individual, and allows precise acuity of self-motion relative to surrounding stimuli through complementary inputs with the vestibular system (Smith, Greenlee, DeAngelis, \& Angelaki, 2017). While the vestibular system provides information regarding self-acceleration, the visual system provides information regarding velocities of either the self or external stimuli. Together the vestibular system and visual system provide complementary inputs. When vision is blurred the vestibular system allows for reflexive movement of the pupils in an effort to maintain visual acuity.

\section{C.1: Vestibulo-Ocular Reflex (VOR): Gaze Stability}

The vestibulo-ocular reflex (VOR) is a compensatory eye movement involving opposite but equal responses to perceived head motion to stabilize gaze while the body is moving (Mahfuz et al., 2018). Gaze stabilization is possible through working unison of the peripheral vestibular system interacting with the six eye muscles of the retina. Vertical eye movements result from the vertical semicircular canals and saccules interacting with the eye muscles. Horizontal eye movements result from the horizontal canals and utricles interacting with the eye muscles. Torsional eye movements result from the vertical semicircular canals and the utricle interacting with the eye muscles. 
To strengthen the VOR, incongruity within the visual field and vestibular stimulation, i.e. head movement while focusing on an immobile object, is a wellpracticed VOR stimuli (Mahfuz et al., 2018). When studying passive versus active VOR training, Mahfuz et al. did not find disparities among passive versus active VOR training. Rather, researchers found velocity, frequency, and acceleration to be the best indicators of VOR training effectiveness. Furthermore, they found subjects training at a low-frequency, low-velocity had a quicker reversal in adaptations following ceased training than subjects trained at highfrequency, high-velocity stimulus. However, when analyzing the effects of visual contrast on VOR training, the authors found quicker VOR adaptations in subjects with a greater visual contrast disparity between the focused object and ambient light.

\section{D: The Vestibular System \& Motor Control}

Research has proven difficult in properly removing vestibular stimulation in response to exercise due to any kind of head movement providing vestibular stimulation (Smith 2017). With the exception of complete bilateral peripheral vestibular lesions, the vestibular system cannot be properly alienated from stimulation due to continuous gravitational pull. However, it can decrease in its required threshold response due to a lack of continuous intense stimulation. Peripheral vestibular stimulation in humans has shown increased activity in the hippocampus when analyzing fMRI and EEG activity. The primary function of the hippocampus is to form declarative short-term memories required for factual retention such as a person's name. The literature shows increased neurogenesis 
in the hippocampus as a result of physical activity, but detaching the vestibular system is difficult to accomplish due to causing irreversible damage. Yasuhara et al. (2007) conducted a study to determine the effects of a lack of exercise on neurogenesis. To eliminate vestibular input the researchers suspended rats from their hindlimbs and tail for 2 weeks. Researchers found that a lack of exercise not only reduced neurogenesis in the hippocampus, but consequently downregulated neurotrophic factors involved in growth, survival, and differentiation of neurons. Furthermore, they found a decrease in activity of the central nervous system.

\section{D.1: The Vestibular System \& Motor Control: Cerebellum}

The cerebellum, attached to the brainstem posteriorly to the pons, consists of three parts that refine motor control (Seeley et al., 2011). The spinocerebellum allows fine motor control through the comparator when conducting simple movements. The comparator is an intrinsic loop of communication highways between the actual movement (peripheral structures) and intended movement (motor cortex). The motor cortex sends information to the spinal cord to initiate voluntary movements while simultaneously sending information to the cerebellum, who simultaneously receives proprioceptive information from the spinocerebellar. The cerebellum compares the information received to the intended movement and fine tunes any variation through the thalamus to the motor cortex and the spinal cord.

The cerebrocerebellum is a specification system involved in planning and executing complex motor activity through the communication with the motor, premotor, and pre-frontal cerebral cortex. It is this specification system that 
allows highly skilled individuals, such as athletes and composers, to quickly and effectively execute complex movements without involving a delayed reaction from the comparator. Furthermore, the cerebrocerebellum is involved in cognitive function involving rhythms, time intervals, and puzzle solving. The third part of the cerebellum, the vestibulocerebellum receives information from the vestibular system to maintain muscle tone, balance, and eye coordination.

\section{E: The Vestibular System \& Somatosensory Interactions}

The peripersonal space, the space immediately adjacent to and surrounding the body, is identified through multisensory somatosensory neuron integrations of touch, pressure, itch, vibration, temperature, proprioception, and pain (Pfeiffer, Noel, Serino, Blanke, 2018). The visual system provides immediate cues about the surrounding world whereas the vestibular system provides information regarding acceleration and head movement. Even more complex is postural control, which is achieved through an intricate interface of visual, vestibular, and somatosensory cues (Harris, Sakurai, \& Beaudot, 2017).

Somatosensory cues provide information about surrounding surfaces relative to the body. Harris et al. concluded that simultaneous tactile and vestibular stimulation did not override visual and vestibular cues, but rather enhanced visual and vestibular stimulation. When analyzing somatosensory dominance Chong, Berl, Cook, Turner, \& Walker (2017) found that individuals with a vestibular disorder relied heavier on somatosensory cues, indicating a compensatory adaptation to a maladaptive vestibular system. 
The fronto-parietal cortical network and the ventral intraparietal and ventral premotor cortex respond to visual, somatosensory, auditory, and vestibular stimuli to localize the source of sound and touch in the external space (Pfeiffer et al., 2018). When stimulating the peripheral vestibular nerve, a response in the secondary somatosensory cortex indicated vestibular inputs are also received by the somatosensory cortex (Cabolis, Steinberg, \& Ferrè, 2018). Vestibular stimulation increases tactile perception, further confirming a multisensory response.

\section{E.1: The Vestibular System \& Somatosensory Interactions: Proprioception}

Unlike most somatic senses, proprioception provides the self with information regarding the position and movement of body parts as well as the required force to perform a task (Enoka 2015). The ability to identify the position

and movement of the self within space and in relation to the external environment allow the self to properly and precisely interact with the surrounding world. An individual is able to stand still without falling or swaying as a response of automatic postural activity. Postural equilibrium is a result of automatic reflexive responses to a displacement of the center of gravity.

The vestibular system, first and foremost, is the most important component for balance. Furthermore, balance is a product of multiple sensory inputs working together. It is the compilation of the multisensory inputs that allow for precise identification surrounding environments to maintain balance and fine motor control. Thus, in theory vestibular stimulation will improve balance and fine motor control. 


\section{Summary and Rationale}

The purpose of this study was to determine if a physical activity program called Minds in Motion-MAZE improves motor proficiency and balance in 6th graders attending Plainfield Community Middle School. Minds in Motion-MAZE is a program specifically designed to improve balance, motor proficiency, and bilateral coordination. It is a low-cost program that can be implemented in any setting.

\section{Aims and hypotheses}

1. Overall aim: To investigate if a physical activity program called Minds in Motion-MAZE improves balance and motor proficiency in middle school aged students attending Plainfield Community Middle School.

a. Specific Aim 1: To evaluate the effects of Minds in Motion-MAZE on balance.

i. Hypothesis 1.1: Students enrolled in Minds in Motion-MAZE showed significantly higher scores of balance than students in the control group.

1.1: Balance will be measured using the Neurocom limit of stability.

b. Specific Aim 2: To evaluate the effects of Minds in Motion-MAZE on motor proficiency.

i. Hypothesis 2.1 Students enrolled in Minds in Motion-MAZE will show significantly higher scores in motor proficiency than students in the control group.

2.1: Motor proficiency will be measured using the BOT-2. 


\section{CHAPTER II}

\section{RESEARCH DESIGN AND METHODS}

\section{A. Ethical Approval for Human Studies}

This study was formally approved by the University of Louisville Institutional Review Board (University of Louisville IRB:17.0287) in compliance with all the institutional and federal regulations concerning the ethical use of human volunteers for research studies.

\section{B. Experimental Procedures}

\section{Facilities/Resources}

The experiment took place at Plainfield Community Middle School located in Plainfield, Indiana. The school is a part of Plainfield Community School Corporation. Plainfield Community Middle School demographics were predominantly Caucasian whom make up $85.3 \%$ of the overall student population. Minds in Motion-Maze took place in the gymnasium of the school thus allowing ample space for the students.

\section{Participants:}

A convenience sample of 74 participants was separated into two groups, the maze group $(n=40)$ and the control group $(n=34)$. Students whose teachers 
agreed to participate in Minds in Motion-MAZE during $7^{\text {th }}$ period made up the experimental group whereas students whose teachers did not participate in Minds in Motion-MAZE made up the control group. Each participant in the experimental group participated in Minds in Motion-MAZE daily for 15 minutes. Participants in the control group received standard instruction as stipulated by Plainfield Community Middle School and Plainfield Community Schools Corporation.

\section{Assessments:}

\subsection{Balance}

Balance was measured using, a computerized force plate (Neurocom, city, state) utilized to measure limit of stability, which is a function to measure balance control and postural stability while moving towards a designated target shown on a computer screen (Juras, Slomka, Fredyk, Sobota, \& Bacik, 2008). The subjects were instructed to remove their shoes but were allowed to keep their socks on. The subject's feet were guided onto the force plate by the researcher per the Neurocom instructions. The subjects were instructed to move towards 1 of 6 digital boxes one box at a time (forward, forward left, backwards left, backwards, backwards right, and forward right) as shown on a screen 2 meters away from the subject's eye level (Juras et al., 2008). Each subject was tested in the same trial order. Prior to initiating each trial, the subject was verbally given the guidelines taken from the Neurocom instructions "Do not move your feet. Do not bend the knees. Do not bend at the hips. Always keep your hands to your side and lean. Once you get there (the digital box) just hold in place". For each trial 
while the subject moved, the force place measured the force required by the subject's body to accomplish the movement as well as postural control and/or adjustments required to maintain equilibrium throughout the movement (Juras et al., 2008). The same limit of stability test using the same Neurocom was conducted during pre-and post-testing.

\subsection{Motor Proficiency}

Motor proficiency was assessed using the Bruininks-Oseretsky Test of Motor Proficiency, Second Edition (BOT-2) (REF) . The BOT-2 is a standardized referenced measurement applicable in a clinical and/or school setting by practitioners and/or researchers (Bruininks 2005; Deitz, Kartin, \& Kopp, 2007). Revised in 2005, the BOT-2 is individually administered to children and youth between the ages of 4 to 21 years old (Bruininks 2005; Deitz et al., 2007). Its purpose is to evaluate fine and gross motor skills by evaluating motor performance, fine manual control, manual coordination, body coordination, strength, and agility (Bruininks 2005; Deitz et al., 2007). The BOT-2 can be provided in the Complete Form (administered in 45-60 minutes) or Short Form (administered in 15-20 minutes) (Bruininks 2005; Deitz et al., 2007). The Short Form consists of 8 subtests and consisted of the following assessments shown in tables 1 to 8 . The same administration was given to all subjects. 
Table 1 Subtest 1: measures fine motor precision

\begin{tabular}{|l|l|}
\hline $\begin{array}{l}\text { Drawing lines through paths- } \\
\text { Crooked }\end{array}$ & $\begin{array}{l}\text { While the researcher ran his/her finger } \\
\text { along the crooked path from the car to } \\
\text { the house he/she explained "draw a line } \\
\text { on the path from the car to the house. } \\
\text { Take your time and try to stay inside the } \\
\text { lines" (as cited in Bruinink, 2005). }\end{array}$ \\
\hline Folding Paper & $\begin{array}{l}\text { The researcher demonstrated folding the } \\
\text { corner of the page labeled "Examiner", } \\
\text { then pointed to a different corner and } \\
\text { instructed the subject "now, you try it. } \\
\text { Fold this corner of the paper on the line. } \\
\text { Now, fold the other corners the same } \\
\text { way." When all corners were folded the } \\
\text { researcher pointed to the middle line and } \\
\text { instructed the subject "now, fold it on this } \\
\text { line" (as cited in Bruininks, 2005). }\end{array}$ \\
\hline
\end{tabular}

Table 2 Subtest 2: measures fine motor integration

\begin{tabular}{|l|l|}
\hline Copying a square & $\begin{array}{l}\text { Pointing to the square already drawing } \\
\text { next to the empty box, the researchers } \\
\text { instructs the subject "draw this shape, } \\
\text { here (pointing to the empty box). Make } \\
\text { it look just the same" (as cited in } \\
\text { Bruininks, 2005). }\end{array}$ \\
\hline Copying a star & $\begin{array}{l}\text { Pointing to the star already drawing } \\
\text { next to the empty box, the researchers } \\
\text { instructs the subject "draw this shape, } \\
\text { here (pointing to the empty box). Make } \\
\text { it look just the same" (as cited in } \\
\text { Bruininks, 2005). }\end{array}$ \\
\hline
\end{tabular}


Table 3 Subtest 3: measures manual dexterity

\begin{tabular}{|l|l|}
\hline Transferring pennies & The penny pad was placed in front of \\
the subject with the pennies on the \\
penny outlines and the box on the box \\
outlined. The subject was shown how \\
to pick up one penny at a time with \\
preferred hand and transfer it to non- \\
preferred hand, and placing penny into \\
box. The subject could practice with 3 \\
pennies before they were returned to \\
their original position on the penny pad. \\
The subject was instructed "now, try it \\
again. Put the pennies into the box as \\
fast as you can until I tell you to step. \\
Ready? Begin." When the researcher \\
said "begin" he/she simultaneously \\
began a timer for 15 seconds before \\
instructing the subject to stop. The \\
subject was instructed to transfer the \\
pennies for 2 trials. (as cited in \\
Bruininks, 2005).
\end{tabular}


Table 4 Subtest 4: measures bilateral coordination

\begin{tabular}{|l|l|}
\hline Jumping in place-same sides & The subject was shown how to stand \\
synchronized & side freferred leg and arm on the same \\
side ford and jumping up while & bringing non-preferred leg and arm on \\
the same side forward with continuous \\
movement. The subject was instructed \\
"jump until I tell you to stop." After 5 \\
correct synchronized continuous jumps \\
the subject was instructed to stop. If an \\
incorrect jump was made by the \\
subject, he/she was instructed to stop \\
and "let's try it again". If the maximum \\
number of 5 jumps was achieved the \\
second trial was not repeated. (as cited \\
in Bruininks, 2005). \\
\hline Tapping feet and fingers-same sides \\
synchronized & $\begin{array}{l}\text { The subject was shown how to sit at a } \\
\text { table with index fingers extended while } \\
\text { the other fingers are tucked in. The } \\
\text { subject was shown how to } \\
\text { simultaneously tap foot and index } \\
\text { finger on the same side of the body. } \\
\text { Then, simultaneously tap the foot and } \\
\text { index finger on the other side of the } \\
\text { body without extended pauses. The } \\
\text { subject was shown how to perform the } \\
\text { task and instructed "tap your feet and } \\
\text { fingers until I tell you to stop." The } \\
\text { subject was instructed to "stop" after 10 } \\
\text { correct taps or an incorrect tap was } \\
\text { performed. When performing an } \\
\text { incorrect tap was performed the subject } \\
\text { was given a second trial with the same } \\
\text { instructions. (as cited in Bruininks, } \\
\text { 2005). }\end{array}$ \\
\hline
\end{tabular}


Table 5 Subtest 5: measures balance

\begin{tabular}{|l|l|}
\hline Walking forward on a line & The line was taped prior to \\
assessments. The subject was shown \\
to stand with feet together with \\
preferred foot on and parallel to the \\
taped line. The subject was shown to \\
place his/her hands on his/her hips and \\
walk forward in a natural walking stride \\
while placing feet on and parallel to the \\
line with each step. The subject was \\
instructed "walk on the line until I tell \\
you to stop". The subject was \\
instructed to "stop" after 6 correct \\
steps. If the subject was not able to \\
complete 6 correct steps a second trial \\
was performed following the same \\
instructions. (as cited in Bruininks, \\
2005). \\
\hline The subject was shown to stand on the \\
balance beam with preferred leg and \\
beam-Eyes open \\
non-preferred leg on the floor. The \\
subject was shown to bring his non- \\
preferred leg to a 90 angle while \\
having hands place on their hips. The \\
subject was instructed "stand on one \\
leg on the beam until I tell you to stop." \\
If the subject was able to maintain their \\
balance for 10 seconds the second trial \\
was not conducted. However, if the \\
subject lost their balance the second \\
trial was conducted. (as cited in \\
Bruininks, 2005).
\end{tabular}


Table 6 Subtest 6: measures running speed and agility

\begin{tabular}{|l|l|}
\hline One-Legged Stationary Hop & $\begin{array}{l}\text { Prior to initiating testing a "T" shaped } \\
\text { line was taped to the floor using yellow } \\
\text { tape per the instructions. The subject } \\
\text { was shown to stand with feet together } \\
\text { on the end line and to maintain hands } \\
\text { on hips while raising non-preferred leg } \\
\text { to a 90ªngle. The subject was shown } \\
\text { to hop up and down on preferred leg } \\
\text { while maintaining proper form with } \\
\text { each form. The subject was instructed } \\
\text { "hop up and down on one leg until I tell } \\
\text { you to stop." The subject hopped for 15 } \\
\text { seconds. The second trial was only } \\
\text { conducted if the subject stumbled or } \\
\text { fell during the first trial. (as cited in } \\
\text { Bruininks, 2005). }\end{array}$ \\
\hline
\end{tabular}

Table 7 Subtest 7: measures upper-limb coordination

\begin{tabular}{|l|l|}
\hline Dropping and Catching a Ball-Both & $\begin{array}{l}\text { The subject was shown to hold a tennis } \\
\text { ball with both hands and to extend } \\
\text { his/her arms in front of their body. The } \\
\text { subject was shown to drop the ball and } \\
\text { catch it with both hands after bouncing } \\
\text { on the floor once. The subject could } \\
\text { practice one bounce and was then } \\
\text { instructed "Now, try it again, Drop and } \\
\text { catch the ball with both hands." (as } \\
\text { cited in Bruininks, 2005). }\end{array}$ \\
\hline Dribbling a Ball-Alternating Hands & $\begin{array}{l}\text { The subject was shown to hold the } \\
\text { tennis ball in preferred hand and while } \\
\text { extending preferred arm in front of their } \\
\text { body to drop the ball and alternate } \\
\text { hands with each dribble. The subject } \\
\text { was instructed "Dribble the ball, } \\
\text { changing hands with each dribble until I } \\
\text { tell you to stop." The subject was } \\
\text { instructed to stop following 10 correct } \\
\text { dribbles. If 10 correct dribbles were not } \\
\text { obtained a second trial was conducted. } \\
\text { (as cited in Bruininks, 2005). }\end{array}$ \\
\hline
\end{tabular}


Table 8 Subtest 8: measures strength

\begin{tabular}{|l|l|}
\hline $\begin{array}{l}\text { Knee Push-Ups } \\
\text { Or } \\
\text { Full Push-Ups }\end{array}$ & $\begin{array}{l}\text { The subject was shown to kneel on the } \\
\text { pad provided and lean forward to put } \\
\text { hands directly behead shoulders. The } \\
\text { subject was shown to cross their } \\
\text { ankles and raise their feet off the floor } \\
\text { while maintaining their back and neck } \\
\text { straight with each push-up. The subject } \\
\text { was instructed "Do knee push-ups until } \\
\text { I tell you to stop." The subject } \\
\text { performed knee push-ups for 30 } \\
\text { seconds. (as cited in Bruininks, 2005). }\end{array}$ \\
\hline The subject was shown to lie on their \\
back on the floor with their arms at their \\
sides and palms down. The subject \\
was shown to bend the knees at a 90 \\
angle with feet flat on the floor. The \\
subject was shown to raise their head, \\
shoulders, and shoulder blades off the \\
floor reaching for their knees and then \\
lowering the body back to the floor. The \\
subject was instructed "Do sit-ups until \\
I tell you to stop." The number of \\
correct sit-ups performed for 30 \\
seconds was recorded. (as cited in \\
Bruininks, 2005).
\end{tabular}

\subsection{Intervention}

\section{Minds in Motion-MAZE}

Minds in Motion-MAZE is set up in a circuit format with various exercises at each station. The participants begin the maze at various stations and move in a clockwise manner. Each student performed the exercise at their specific station for one minutes before rotating to the next station. The intervention was 15 minutes a day Monday thru Friday during $7^{\text {th }}$ period. Each week the maze will increase in intensity for the required exercises. Each week, prior to initiation, 
each exercise of the maze will be explained by the student's teacher. The same teacher will conduct the maze for the student throughout the study. The exercises are per Appendix A.

\section{Experimental Design:}

A true experimental design will be used to examine the effectiveness of Minds in Motion-MAZE program. Specifically, a convenience sample of 74 students will be part of the control group (no Minds in Motion) or experimental group (Minds in Motion in 7th period). The selection is based on teacher preference on incorporating Minds in Motion-MAZE into their curriculum or not.

\section{Data Analysis:}

Descriptive and inferential statistics will be used to assess program effectiveness. Descriptive statistics will be used to understand characteristics of the study sample. This includes: fine motor skills based on BOT-2 scores and balance based on limit of stability scores. A multivariate analysis of variance (MANOVA) will be used to examine the effectiveness of Minds in Motion-MAZE program with treatment groups as the independent variable (treatment and control) and two dependent variables. The MANOVA provides a simultaneous test of the similarity of scores across dependent variables, thus controlling the likelihood of a Type I error associated with conducting two separate univariate tests. Specifically, the MANOVA provides a basis to judge whether score differences exist on the dependent variables. Statistically significant findings would signal the groups differ on at least one of the dependent variable and, subsequently, a univariate comparison would be conducted to identify the 
dependent variable that the groups differ. An effect size using omega squared will be used to report the percent of variability in the dependent variable attributable to treatment groups. 


\section{CHAPTER III}

\section{RESULTS}

Table 9 shows the sample size for the control, no Minds in Motion-MAZE, and the experimental, Minds in Motion-MAZE to be 30 and 33 respectively when

\begin{tabular}{|ll|l|r|}
\hline \multicolumn{3}{|c|}{ Table 9: Balance Sample Size } \\
\hline & Value Label & \multicolumn{1}{|c|}{ N } \\
\hline \multirow{2}{*}{ Group } & 1.000 & NO MIM & 30 \\
& 2.000 & MIM & 33 \\
\hline
\end{tabular}
analyzing balance. Tables 10 to 17 show the multivariate tests results when analyzing reaction time, movement velocity, endpoint, maximum excursion, and directional control on the limit of stability when moving forward, right forward, right, right backward, backward, left backward, left, and left forward. Table 10 indicates the pre and post values for reaction time for the control (NO MIM) and experimental (MIM) groups when moving forward, right forward, right, right backward, backward, left backward, left, left forward. Most $p$-values were greater than .05 for all directions for both groups except for the experimental (MIM) group

\begin{tabular}{|c|c|c|c|c|c|c|c|c|c|c|}
\hline & & & & & & & & Left & & \\
\hline Measure & Group & Time & Forward & Right Forward & Right & Right Backward & Beckward & Backward & Left & Left Forward \\
\hline \multirow[t]{7}{*}{ Reaction Time } & \multirow[t]{3}{*}{ Control } & Pre & $1.08(0.58)$ & $0.93(0.38)$ & 0.86 (0.32) & $0.84(0.46)$ & $0.7(0.35)$ & $0.8(0.42)$ & $0.67(0.28)$ & $0.77(0.29)$ \\
\hline & & Post & $0.9(0.48)$ & $0.83(0.34)$ & $0.68(0.25)$ & $0.62(0.31)$ & $0.62(0.33)$ & $0.81(0.43)$ & $0.63(0.23)$ & $0.67(0.29)$ \\
\hline & & P-values & 0.461 & 0.461 & 0.244 & 0.181 & 0.535 & 0.929 & 0.929 & 0.181 \\
\hline & \multirow[t]{4}{*}{ Experimental } & Pre & $1.22(0.57)$ & $0.92(0.38)$ & $0.76(0.32)$ & $0.73(0.35)$ & $0.64(0.38)$ & $0.78(0.38)$ & $0.65(0.24)$ & $0.68(0.24)$ \\
\hline & & Post & $0.85(0.42)$ & $0.8(0.36)$ & $0.71(0.26)$ & $0.6(0.26)$ & $0.67(0.32)$ & $0.68(0.27)$ & $0.68(0.25)$ & $0.62(0.24)$ \\
\hline & & P-values & 0.004 & 0.201 & 0.773 & 0.152 & 0.773 & 0.012 & 0.762 & 0.488 \\
\hline & & rimental & 0.734 & 0.515 & 0.759 & 0.515 & 0.585 & 0.759 & 0.515 & 0.849 \\
\hline
\end{tabular}


when moving forward $p<.05$. Table 11 indicates the pre and post values for movement velocity for the control (NO MIM) and experimental (MIM) groups when moving forward, right forward, right, right backward, backward, left backward, left, left forward. Few statistical significances were observed when moving left forward for the control (NO MIM) group, $p<.05$. Additionally,

\begin{tabular}{|c|c|c|c|c|c|c|c|c|c|c|}
\hline \multicolumn{11}{|c|}{ Table 11: Limit of Stability Movement Velocity } \\
\hline Measure & Group & Time & Forward & Right Forward & Right & Right Backward & Backward & Backward & Left & Left Forward \\
\hline \multirow[t]{6}{*}{ Movement Velocity } & Control & Pre & $4.7(1.38)$ & $5.19(1.56)$ & $6.38(3.07)$ & $5.1(2.28)$ & $2.9(1.7)$ & $4.41(1.9)$ & $6.29(2.68)$ & $7.2(2.73)$ \\
\hline & & Post & $5.19(2.19)$ & $5.94(1.97)$ & $5.86(2.52)$ & $4.69(2.46)$ & $2.56(1.29)$ & $4.29(2.11)$ & $6.36(2.67)$ & $6.27(2.19)$ \\
\hline & & P-values & 0.881 & 0.527 & 0.527 & 0.527 & 0.527 & 0.616 & 0.527 & 0.03 \\
\hline & Experimental & Pre & $5.18(2.61)$ & $5.79(2.17)$ & $6.72(2.71)$ & $5.32(1.92)$ & $3.06(1.4)$ & $5.01(2.11)$ & $6.54(2.25)$ & $7.33(2.92)$ \\
\hline & & Post & $4.71(2.23)$ & $5.16(2.15)$ & $5.66(2.35)$ & $4.9(3.48)$ & $3.04(1.02)$ & $4.44(2)$ & $5.11(2.04)$ & $6.51(2.46)$ \\
\hline & & P-values & 0.368 & 0.096 & 0.237 & 0.123 & 0.383 & 0.146 & 0.011 & 0.087 \\
\hline
\end{tabular}

statistical significance was observed in the experimental (MIM) group, $p<.05$.

Table 12 indicates that weren't any statistical significances observed in endpoint variables in aby direction for the control (NO MIM) and the experimental (MIM) group.

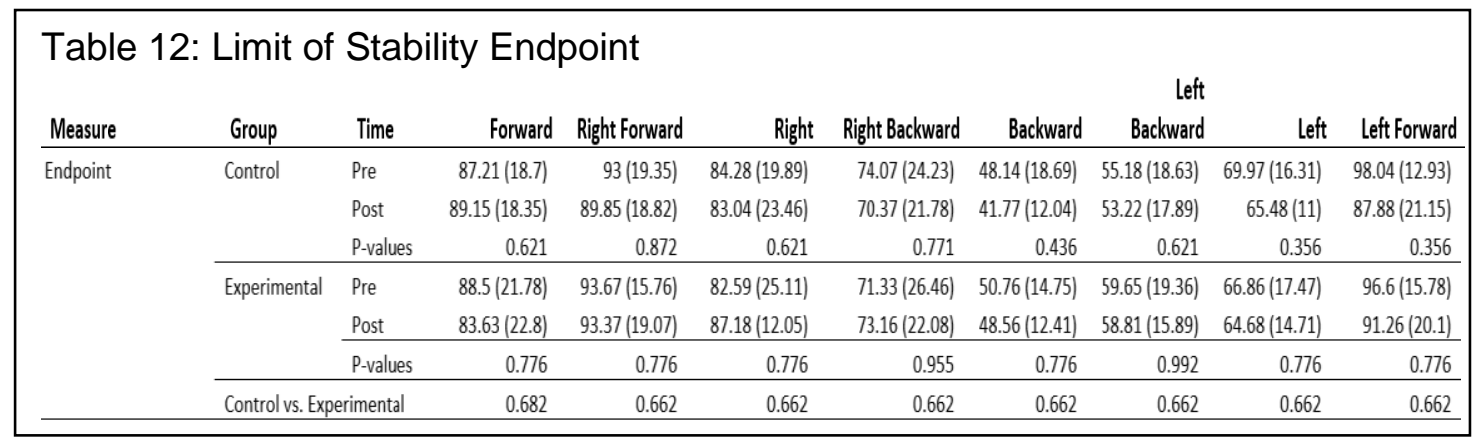

Table 13 indicates statistical significances were observed in the control (NO MIM) group for maximum excursion when moving left forward and left, $p<.05$. The experimental (MIM) saw statistically significant changes in maximum excursion when moving left and right, $p<.05$. Table 14 indicates a statistical 
significance for the control (NO MIM) group for directional control when moving back and right forward. However, there weren't any statistical significance observed for the experimental (MIM) group.

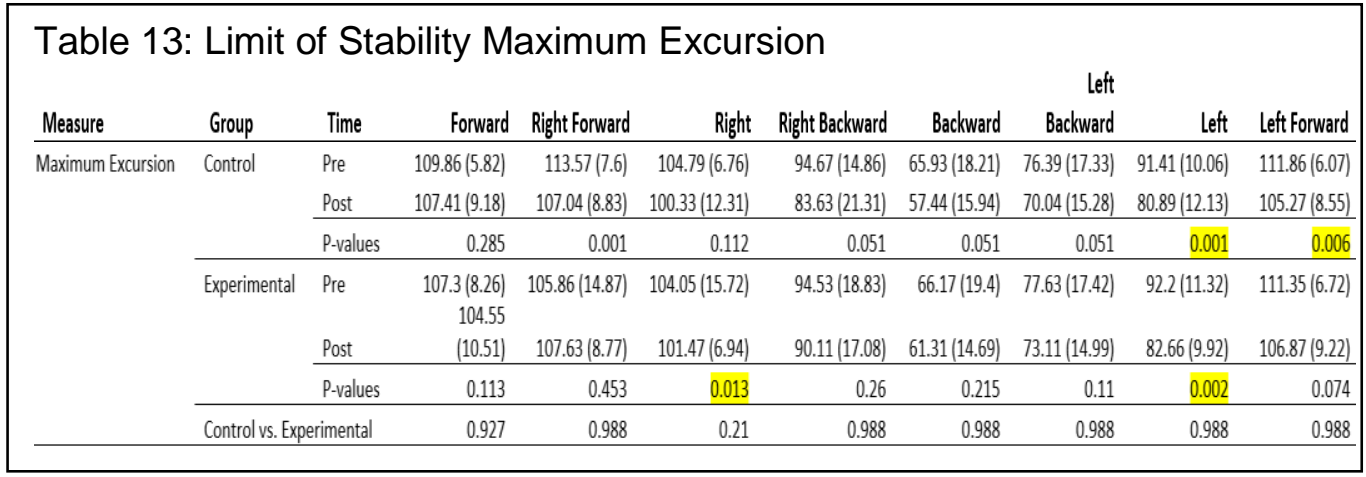

\begin{tabular}{|c|c|c|c|c|c|c|c|c|c|c|}
\hline Measure & Group & Time & Forward & Right Forward & Right & Right Backward & Backward & $\begin{array}{r}\text { Left } \\
\text { Backward }\end{array}$ & Left & Left Forward \\
\hline \multirow[t]{6}{*}{ Directional Control } & Control & Pre & $90.82(5.96)$ & $76.79(15.93)$ & $86.07(6.6)$ & $60.89(13.05)$ & 50.38 (20.71) & 46.15 (19.83) & $73.93(13.76)$ & $83.25(8.75)$ \\
\hline & & Post & $89.96(3.72)$ & $83.19(9.29)$ & $86.3(6.88)$ & 55.35 (18.19) & 55.04 (19.69) & $57(19.01)$ & $74.48(10.2)$ & $83.81(8.29)$ \\
\hline & & P-values & 0.871 & 0.042 & 0.871 & 0.823 & 0.02 & 0.051 & 0.871 & 0.89 \\
\hline & Experimental & Pre & 85.86 (14.11) & $79.72(15.56)$ & $83.93(8.12)$ & $58.83(16.65)$ & $50.26(21.56)$ & $46.62(18.76)$ & $72.16(17.2)$ & $82.51(8.97)$ \\
\hline & & Post & $87.03(11.7)$ & $79.34(8.48)$ & $85.21(7.03)$ & $67.97(18.36)$ & $57.97(23.09)$ & $52.09(15.1)$ & $75.05(9.52)$ & $80.58(8.65)$ \\
\hline & & P.values & 0.265 & 0.957 & 0.265 & 0.056 & 0.265 & 0.78 & 0.78 & 0.612 \\
\hline
\end{tabular}

Overall no statistical significant relationship was observed between participating in Minds in Motion-MAZE and balance on the limit of stability when measuring reaction time, movement velocity, endpoint, maximum excursion, and directional control as graphed in Figure 1. Table 15 shows the sample size for the control and experimental group when conducting the BOT-2. The multivariate tests for total points scored on the BOT-2 does not show a

\begin{tabular}{|} 
Table 15: BOT-2 Sample Size \\
\begin{tabular}{|ll|l|r|}
\hline & Value Label & \multicolumn{1}{c|}{ N } \\
\hline \multirow{3}{*}{ Group } & 1.000 & NO MIM & 33 \\
& 2.000 & MIM & 34 \\
\hline
\end{tabular}
\end{tabular}


significant difference among the control and experimental group, $F(2,64)=$ $1.009, p>.05$ (Table 16).

\begin{tabular}{|l} 
Table 16: BOT-2 Total Points Scored \\
\begin{tabular}{|ll|r|r|r|r|r|}
\hline Effect & & Vultivariate Tests & \\
\hline & & Value & \multicolumn{1}{c|}{ F } & Hypothesis df & Error df & Sig. \\
\hline \multirow{6}{*}{ Intercept } & Pillai's Trace & .992 & $3987.966^{\mathrm{b}}$ & 2.000 & 64.000 & .000 \\
& Wilks' Lambda & .008 & $3987.966^{\mathrm{b}}$ & 2.000 & 64.000 & .000 \\
& Hotelling's Trace & 124.624 & $3987.966^{\mathrm{b}}$ & 2.000 & 64.000 & .000 \\
& Roy's Largest Root & 124.624 & $3987.966^{\mathrm{b}}$ & 2.000 & 64.000 & .000 \\
& Pillai's Trace & .031 & $1.009^{\mathrm{b}}$ & 2.000 & 64.000 & .370 \\
& Wilks' Lambda & .969 & $1.009^{\mathrm{b}}$ & 2.000 & 64.000 & .370 \\
Group & Hotelling's Trace & .032 & $1.009^{\mathrm{b}}$ & 2.000 & 64.000 & .370 \\
& Roy's Largest Root & .032 & $1.009^{\mathrm{b}}$ & 2.000 & 64.000 & .370 \\
\hline
\end{tabular}
\end{tabular}

The multivariate tests for percentile rank on the BOT-2 does not show a significant difference among the control and experimental group, $F(2,64)=$ 1.603, $p>.05$ (Table 17). No significant relationship was observed among fine motor control and participating in Minds in Motion-MAZE.

\begin{tabular}{|c|c|c|c|c|c|c|}
\hline \multicolumn{7}{|c|}{ Table 17: BOT-2 Percentile Rank } \\
\hline Effect & & Value & $\mathrm{F}$ & Hypothesis df & Error df & Sig. \\
\hline \multirow{4}{*}{ Intercept } & Pillai's Trace & .713 & $79.535^{b}$ & 2.000 & 64.000 & .000 \\
\hline & Wilks' Lambda & .287 & $79.535^{b}$ & 2.000 & 64.000 & .000 \\
\hline & Hotelling's Trace & 2.485 & $79.535^{b}$ & 2.000 & 64.000 & .000 \\
\hline & Roy's Largest Root & 2.485 & $79.535^{b}$ & 2.000 & 64.000 & .000 \\
\hline \multirow{4}{*}{ Group } & Pillai's Trace & .048 & $1.603^{b}$ & 2.000 & 64.000 & 209 \\
\hline & Wilks' Lambda & .952 & $1.603^{b}$ & 2.000 & 64.000 & .209 \\
\hline & Hotelling's Trace & .050 & $1.603^{b}$ & 2.000 & 64.000 & .209 \\
\hline & Roy's Largest Root & .050 & $1.603^{b}$ & 2.000 & 64.000 & 209 \\
\hline
\end{tabular}


Figure 1: Limit of Stability Graphed Results

Reaction Time

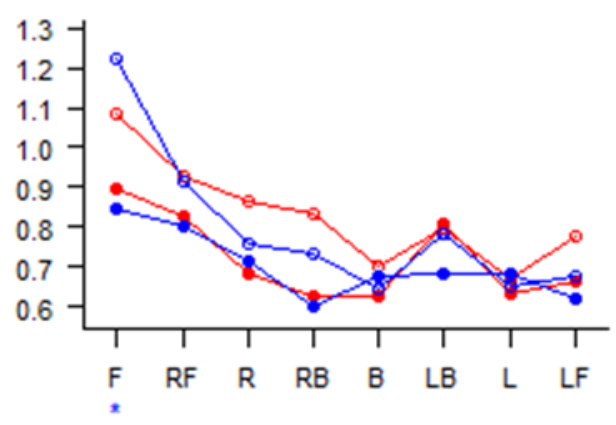

Maximum Excursion

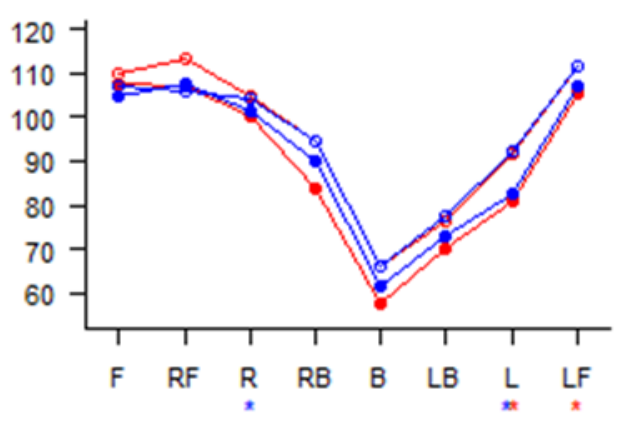

Endpoint

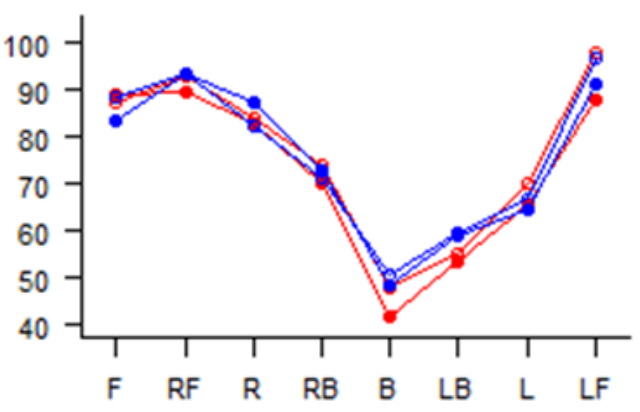

Movement Velocity

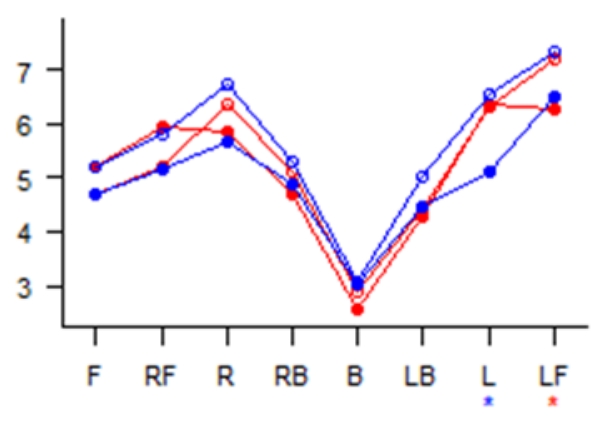

Directional Control

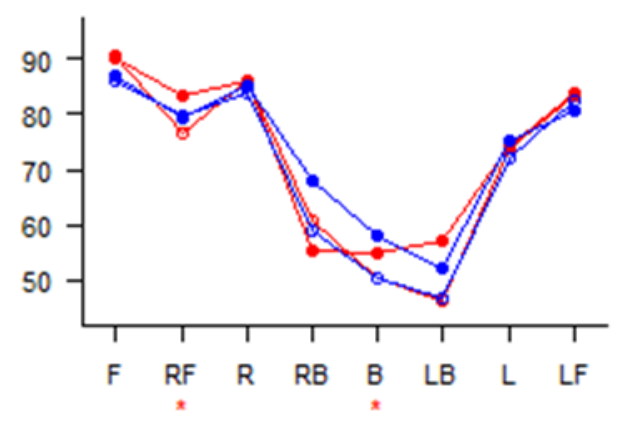

Statistical significance is indicated by a dot underneath the direction of the corresponding group and in the corresponding color.

$F$ : forward

$R F$ : right forward

R: right

RB: right backward

B: back

LB: left backwards

$L$ : left

LF: left forwards 


\section{CHAPTER IV}

\section{DISCUSSION}

With less than $20 \%$ of students achieving the physical activity recommendation of 150 mins/wk, a lack of physical activity among students is a problem that needs to be addressed (Policy Position Statement on Physical Education in Schools, 2008; Slater et al., 2012; Couturier et al., 2014). Donnelly et al. (2017) observed the effects of physically active academic lessons on academic achievements tests and found that regardless of physical activity performed indoors or outdoors, improvements in academic achievement tests was observed. Minds

The increase in vertigo complaints among school aged children is alarming. An increase from $29.9 \%$ to $75 \%$ of children complaining of dizziness and balance issues requires further researcher into effective low-cost forms of stimulating the vestibular system (Li et al., 2016). The vestibular system, although primarily provides information regarding head movement, orientation, and balance, is a multisensory integration of auditory cues, visual cues, motor control, somatosensory cues, and proprioceptive cues. Consequently, it requires a dynamic approach. Studies on the vestibular system have looked at the 
vestibular system in parts but it is a whole system that requires an approache from various angles (Ifediba, Rajguru, Hullar, \& Rabbit, 2007; Mahfuz et al., 2018; Smith 2017). Smith (2017) found that any form of physical activity provides vestibular stimulation. However, the specifics of the type of physical activity that produce the most vestibular stimulation have yet to be answered. 


\section{CHAPTER V}

\section{SUMMARY}

In summary there were minimal statistical significant changes observed but overall there were no statistical significant relationships seen among participating in Minds in Motion-MAZE and the effects on balance and fine motor control. This may be due to a small sample size and lack of heterogeneity. Furthermore, physical activity outside of Minds in Motion-MAZE was not controlled. Plainfield Community Middle School is a school with a physical education component where all participants, regardless of being in the control or experimental group, would have had access to physical activity. Thus, further limiting the study.

\section{CONCLUSIONS}

In conclusion, Minds in Motion-MAZE is an effective way to increase physical activity among school aged children while in a school setting. Despite not showing a statistical significance on balance and fine motor control, Minds in Motion-MAZE is an effective tool for schools to utilize to increase physically activity breaks while school aged children are on school. Studies show active academic lessons improve a student's performance. 
Any form of physical activity is shown to stimulate the vestibular system. It is movement that stimulates the vestibular system. Increasing physical activity is an issue that plagues schooled aged children and requires immediate attention. In schools with limited funding, a low-cost physical activity program, like Minds in Motion-MAZE can increase physical activity among its students at a low cost.

Further direction should include a larger size with heterogeneity. As well as control for physical activity outside of the study. Electroencephalography activity should be considered for future studies to determine neural activity when participating in Minds in Motion-MAZE. Furthermore, the viability of a consistent low-cost physical activity break should be considered a source for schools without a physical education component in the curriculum. 


\section{REFERENCES}

America, S. H. A. P. E., Couturier, L., Chepko, S., \& Holt, S. A. (2014). National standards \& grade-level outcomes for K-12 physical education. Human Kinetics.

Belton, S., Prior, P., Wickel, E., \& Woods, C. (2017). The impact of participation in extra-curricular physical activity on males from disadvantaged schools. European Physical Education Review, 23(1), 60-72.

Bruininks, B. D. (2005). Bruininks-Oseretsky Test of Motor Proficiency: BOT-2. NCS Pearson/AGS.

Cabolis, K., Steinberg, A., \& Ferrè, E. R. (2018). Somatosensory modulation of perceptual vestibular detection. Experimental Brain Research, 1-7.

Chen, W., Hammond-Bennett, A., \& Hypnar, A. (2017). Examination of motor skill competency in students: evidence-based physical education curriculum. BMC public health, 17(1), 222.

Chong, R., Berl, B., Cook, B., Turner, P., \& Walker, K. (2017). Individuals with a vestibular-related disorder use a somatosensory-dominant strategy for postural orientation after inclined stance. Acta Neurologica

Cohen RA and Zammitti EP. Health insurance coverage: Early release of quarterly estimates from the National Health Interview Survey, January 2010-September 2017. National Center for Health Statistics. February 2018. Available from: https://www.cdc.gov/nchs/nhis/releases.htm.

Deitz, J. C., Kartin, D., \& Kopp, K. (2007). Review of the Bruininks-Oseretsky test of motor proficiency, (BOT-2). Physical \& occupational therapy in pediatrics, 27(4), 87-102. 
Donnelly, J. E., Hillman, C. H., Greene, J. L., Hansen, D. M., Gibson, C. A., Sullivan, D. K., ... \& Herrmann, S. D. (2017). Physical activity and academic achievement across the curriculum: Results from a 3-year cluster-randomized trial. Preventive Medicine, 99, 140-145.

Enoka, R. (2015). Neuromechanics of Human Movement Fifth Edition. Champaign, IL. Human Kinetics.

Fitzpatrick, R. C., \& Watson, S. R. (2015). Passive motion reduces vestibular balance and perceptual responses. The Journal of physiology, 593(10), 2389-2398.

Haapala, E. A., Väistö, J., Lintu, N., Westgate, K., Ekelund, U., Poikkeus, A. M., ... \& Lakka, T. A. (2017). Physical activity and sedentary time in relation to academic achievement in children. Journal of science and medicine in sport, 20(6), 583-589.

Harris, L. R., Sakurai, K., \& Beaudot, W. H. (2017). Tactile flow overrides other cues to self motion. Scientific reports, 7(1), 1059.

Hastie, P. A. (2017). Revisiting the National Physical Education Content Standards: What Do We Really Know About Our Achievement of the Physically Educated/Literate Person?. Journal of Teaching in Physical Education, 36(1), 3-19.

Hood, N. E., Colabianchi, N., Terry-McElrath, Y. M., O'Malley, P. M., \& Johnston, L. D. (2014). Physical activity breaks and facilities in US secondary schools. Journal of School Health, 84(11), 697-705.

Ifediba, M. A., Rajguru, S. M., Hullar, T. E., \& Rabbitt, R. D. (2007). The role of 3canal biomechanics in angular motion transduction by the human vestibular labyrinth. Annals of biomedical engineering, 35(7), 1247-1263.

Iversen, M. M., \& Rabbitt, R. D. (2017). Wave Mechanics of the Vestibular Semicircular Canals. Biophysical journal, 113(5), 1133-1149.

Juras, G., Słomka, K., Fredyk, A., Sobota, G., \& Bacik, B. (2008). Evaluation of the limits of stability (LOS) balance test. Journal of Human Kinetics, 19, 39-52. 
Li, C., MD, PhD, Hoffman, H., MA, Ward, B., MD, Cohen, H., EdD, OTR, \& Rine, R., PT, PhD. (2016). Epidemiology of dizziness and balance problems in children in the united states: A population-Based study. The Journal of Pediatrics, 171, 240-247. doi:10.1016/j.jpeds.2015.12.002

Mahfuz, M. M., Schubert, M. C., Figtree, W. V., Todd, C. J., Khan, S. I., \& Migliaccio, A. A. (2018). Optimal Human Passive Vestibulo-Ocular Reflex Adaptation Does Not Rely on Passive Training. Journal of the Association for Research in Otolaryngology, 1-11.

Mahfuz, M. M., Schubert, M. C., Todd, C. J., Figtree, W. V., Khan, S. I., \& Migliaccio, A. A. (2018). The Effect of Visual Contrast on Human Vestibulo-Ocular Reflex Adaptation. Journal of the Association for Research in Otolaryngology, 19(1), 113-122.

O’Mara, A., Rowland, J. H., Greenwell, T. N., Wiggs, C. L., Fleg, J., Joseph, L., ... \& Bray, R. (2017). National Institutes of Health Research Plan on Rehabilitation NIH Medical Rehabilitation Coordinating Committee. Physical Therapy, 97(4), 404-407.

Pacheco, S. C., Gabbard, C., Ries, L. G. K., \& Bobbio, T. G. (2016). Interlimb coordination and academic performance in elementary school children. Pediatrics international, 58(10), 967-973.

Pfeiffer, C., Noel, J. P., Serino, A., \& Blanke, O. (2018). Vestibular modulation of peripersonal space boundaries. European Journal of Neuroscience.

Pfeiffer, C., Serino, A., \& Blanke, O. (2014). The vestibular system: a spatial reference for bodily self-consciousness. Frontiers in integrative neuroscience, 8, 31.

Policy Position Statement on Physical Education in Schools. Dallas, TX: American Heart Association; 2008. http://www.heart.org/idc/groups/heartpublic/@wcm/@adv/documents/downloadable/ucm 301654.pdf. Accessed October 27, 2017

Purves D, Augustine GJ, Fitzpatrick D, et al., editors. Neuroscience. 2nd edition. 
Sunderland (MA): Sinauer Associates; 2001. The Otolith Organs: The Utricle and Sacculus. Available from:

https://www.ncbi.nlm.nih.gov/books/NBK10792/

Santos, C. F., Belinha, J., Gentil, F., Parente, M., Areias, B., \& Jorge, R. N. (2017). Biomechanical Study of the Vestibular System of the Inner Ear Using a Numerical Method. Procedia IUTAM, 24, 30-37.

Seeley, R., VanPutte, C., Regan, J., Russo, A. (2011). Seeley's Anatomy \& Physiology, Ninth Edition. New York, NY: The McGraw-Hill Companies, Inc.

Slater, S. J., Nicholson, L., Chriqui, J., Turner, L., \& Chaloupka, F. (2012). The impact of state laws and district policies on physical education and recess practices in a nationally representative sample of US public elementary schools. Archives of pediatrics \& adolescent medicine, 166(4), 311-316.

Smith, A. T., Greenlee, M. W., DeAngelis, G. C., \& Angelaki, D. E. (2017). Distributed visual-vestibular processing in the cerebral cortex of man and macaque. Multisensory Research, 30(2), 91-120.

Smith, P. F. (2017). Is hippocampal neurogenesis modulated by the sensation of self-motion encoded by the vestibular system?. Neuroscience \& Biobehavioral Reviews.

Turner, L., \& Chaloupka, F. J. (2017). Reach and implementation of physical activity breaks and active lessons in elementary school classrooms. Health Education \& Behavior, 44(3), 370-375.

Wrotniak, B. H., Epstein, L. H., Dorn, J. M., Jones, K. E., \& Kondilis, V. A. (2006). The relationship between motor proficiency and physical activity in children. Pediatrics, 118(6), e1758-e1765.

Yasuhara, T., Hara, K., Maki, M., Matsukawa, N., Fujino, H., Date, I., \& Borlongan, C. V. (2007). Lack of exercise, via hindlimb suspension, impedes endogenous neurogenesis. Neuroscience, 149(1), 182-191.

Ziegler, P., Wahl, P., \& Eberhard, P. (2017). Vibration of the Basilar Membrane and Fluid Pressure Distribution in the Human Cochlea. PAMM, 17(1), 229230. 


\section{Appendix A}

Minds in Motion Exercises

\begin{tabular}{|c|l|}
\hline Exercise: & \multicolumn{1}{|c|}{ Description: } \\
\hline Eye Tracking & $\begin{array}{l}\text { Instructor stand in front of student } \\
\text { and moves pencil in front of } \\
\text { student's eyes (approx. 14" away) } \\
\text { while student follows the object } \\
\text { with his/her eyes. }\end{array}$ \\
\hline Power Skip & $\begin{array}{l}\text { Student skips down a designated } \\
\text { "lane" while swinging their arms } \\
\text { cross laterally in an exaggerated } \\
\text { fashion. }\end{array}$ \\
\hline Midline Touch & $\begin{array}{l}\text { Student slowly walks a given } \\
\text { distance lifting knees high while } \\
\text { touching alternating knees with } \\
\text { opposite hand. }\end{array}$ \\
\hline
\end{tabular}




\begin{tabular}{|c|l|}
\hline Power Push & $\begin{array}{l}\text { Student stands facing a wall then } \\
\text { pushes against the wall with the } \\
\text { palm of their hands and/or pushes } \\
\text { against the floor in an inverted } \\
\text { handstand, with feet against the } \\
\text { wall. }\end{array}$ \\
\hline Tumble Roll & $\begin{array}{l}\text { Student rolls on a mat on the floor } \\
\text { in a predetermined manner or does } \\
\text { somersaults. }\end{array}$ \\
\hline Eye Convergence & $\begin{array}{l}\text { Student holds a beaded string (3 } \\
\text { beads affixed to a string) in their } \\
\text { hand and focuses on each } \\
\text { differently colored bead one at a } \\
\text { time while counting to 10 for each } \\
\text { bead. }\end{array}$ \\
\hline Broad Jump & $\begin{array}{l}\text { Student does a standing broad } \\
\text { jump between two (or more) } \\
\text { designated line drawn or taped to } \\
\text { the floor. }\end{array}$ \\
\hline Balance Board & $\begin{array}{l}\text { Student stands on wooden balance } \\
\text { board training their body to } \\
\text { suspend in balance. } \\
\text { Simultaneously students toss and } \\
\text { catch a bean bag or bounce a ball } \\
\text { as directed. }\end{array}$ \\
\hline $\begin{array}{l}\text { Student spins on a rotational board } \\
\text { board in a variety of manner to } \\
\text { develop greater balance. }\end{array}$ \\
\hline Balance
\end{tabular}




\begin{tabular}{|c|c|c|}
\hline & $\begin{array}{l}\text { in a variety of positions for a given } \\
\text { number of times each way (to the } \\
\text { right and to the left) or for a given } \\
\text { time each way. }\end{array}$ & 21 \\
\hline Step-Ups & $\begin{array}{l}\text { Student walks backward up or } \\
\text { down a set of stairs holding onto a } \\
\text { rail for support. }\end{array}$ & \\
\hline Jump Rope & $\begin{array}{l}\text { Student jumps rope forward and/or } \\
\text { backwards. }\end{array}$ & \\
\hline Rebounder & $\begin{array}{l}\text { Student jumps a given number of } \\
\text { times following the arm patterns on } \\
\text { the laterality/directionality poster. }\end{array}$ & \\
\hline Plyo Jumps & $\begin{array}{l}\text { Student alternates jogging } \\
\text { homolaterally and jogging } \\
\text { bilaterally forward and opposite } \\
\text { arm forward, switching arm and } \\
\text { foot with each jogging action. }\end{array}$ & \\
\hline Agility Ladder & $\begin{array}{l}\text { Student uses an agility ladder (or } \\
\text { taped off ladder) placed on the floor } \\
\text { to jump in different patterns } \\
\text { increasing skill levels as the weeks } \\
\text { progress. }\end{array}$ & \\
\hline $\begin{array}{l}\text { Alternative } \\
\text { Stations }\end{array}$ & $\begin{array}{l}\text { Superman: Laying on your belly, lift } \\
\text { shoulders and legs off the floor. } \\
\text { Laying on your right or left side, lift } \\
\text { shoulders and legs off the floor. }\end{array}$ & \\
\hline
\end{tabular}




\begin{tabular}{|l|l|}
\hline $\begin{array}{l}\text { Core Balance: Plank with hands on } \\
\text { an exercise ball and feet on the } \\
\text { floor. }\end{array}$ \\
\hline
\end{tabular}




\section{Sample Schedule}

\begin{tabular}{|c|c|}
\hline 1. EYE TRACKING & $\begin{array}{l}\text { Instructor stands in front of student and moves pencil slowly (with bright topper or eraser) in front of student's eyes } \\
\text { (app. } 14 \text { " away) while student follows the object with his/her eyes. Instructor moves the pencil in the following } \\
\text { pattern: } 4 \text { horizontal - } 4 \text { vertical - } 4 \text { clockwise circles - } 4 \text { counterclockwise circles - } 4 \text { moving toward nose }\end{array}$ \\
\hline 2. POWER SKIP & Skip along designated path with your arms pumping cross-laterally. \\
\hline 3. BODY ROTATIONS & $\begin{array}{l}\text { Spin } 5 \text { times clockwise and } 5 \text { times counterclockwise: Monday - Crisscross; Tuesday - Superman; Wednesday - Pike; } \\
\text { Thursday - Tuck; Friday - } 360^{\circ} \text { - Stand-n-Spin }\end{array}$ \\
\hline 4. MIDLINE TOUCH & $\begin{array}{l}\text { Slowly walk a given distance lifting knees high while touching alternating knee with opposite elbow while other arm is } \\
\text { held out to side }\end{array}$ \\
\hline 5. JUMP ROPE & Jump rope: Even Days - Forward; Odd Days - backward \\
\hline $\begin{array}{l}\text { 6. OBLIQUE TWIST(OT)/ } \\
\text { PLYO JUMPS (PJ) }\end{array}$ & $\begin{array}{l}\text { OT: Using a large exercise ball or weighted ball, move ball from the upper position to the lower position touching just } \\
\text { outside the opposite foot: Even Days - Upper right to lower left; Odd Days - Upper left to lower right }\end{array}$ \\
\hline 7. REBOUNDER & $\begin{array}{l}\text { Follow the arm pattern of the Laterality/Directionality poster: [Jumps per picture/icon] Monday - } 4 \text { jumps; Tuesday - } 6 \\
\text { jumps; Wednesday - } 3 \text { jumps; Thursday - } 5 \text { jumps; Friday - } 9 \text { jumps }\end{array}$ \\
\hline 8. AGILITY LADDER & $\begin{array}{l}\text { Using the agility ladder, stand on both feet at the beginning of the ladder.BOX\#1: LEFT FOOT in, RIGHT FOOT } \\
\text { in...continue on into each box. Even Days - forward; Odd Days - backward }\end{array}$ \\
\hline 9. STEP UPS & $\begin{array}{l}\text { Walk up the stairs holding on to rail as needed for support. Even Days - walk up backward (alternating the foot you } \\
\text { step with); Odd Days - walk up sideway (change directions each time at the bottom of the steps) }\end{array}$ \\
\hline 10. BALANCE BOARD & While balancing on a balance board, toss and catch a bean bag with both hands; always follow the bag with your eyes. \\
\hline 11. POWER PUSH & $\begin{array}{l}\text { Even Days - Stand facing the wall, push against the wall with the palms of your hands. } \\
\text { Odd Days - Do a handstand...place your hands on the floor and feet against the wall for balance. }\end{array}$ \\
\hline 12. TUMBLE ROLL & $\begin{array}{l}\text { Even Days - Roll on a mat on the floor with both arms stretched above head as straight as possible. Roll down to the } \\
\text { end of mat, then roll back to beginning. Flip over to put head at other side, roll down \& roll back. Repeat pattern. Odd } \\
\text { Days - Do a forward somersault. (head down / chin to chest /roll straight over the top) }\end{array}$ \\
\hline 13. EYE CONVERGENCE & $\begin{array}{l}\text { Hold end of "Eye Beads" string perpendicular against your nose and focus on each differently colored bead, one at a } \\
\text { time, while counting to } 10 \text { for each bead. Even Days - Longer string; Odd Days - Shorter string; Even Weeks - Hold } \\
\text { string with RIGHT HAND; Odd Weeks - Hold string with LEFT HAND }\end{array}$ \\
\hline 14. LINEAR BALANCE & $\begin{array}{l}\text { Walk on long wooden boards ("the beam"), heel-toe, with your head up. Turn around at the end without stepping off } \\
\text { the beam. Even Days - forward; Odd Days - backward }\end{array}$ \\
\hline 15. BROAD JUMP & $\begin{array}{l}\text { Do a standing broad jump between several designated lines drawn or taped on the floor. } \\
\text { Even Days - Jump forward; Odd Days - Jump backward }\end{array}$ \\
\hline
\end{tabular}




\section{CURRICULUM VITAE \\ Liliana J. Vargas, B.A.}

ljvarg01@louisville.edu

\section{Education:}

May, 2018 Masters of Science in Exercise Physiology, Concentration: Clinical Exercise Physiology University of Louisville, Louisville, $\mathrm{KY}$

Thesis: "Effects of a physical activity program called "Minds-inMotion- the MAZE" on balance and motor skills in middle school aged students"

Faculty Advisor: Daniela Terson de Paleville, $\mathrm{PhD}$

Current GPA: 3.80

May, 2011 Bachelors of Art in Psychology

California State University, Channel Islands, Channel Islands, CA Cum GPA: 3.0

\section{Presentations:}

Liliana Vargas, Jason Immekus, Daniela Terson de Paleville. Gravity Falls: The relationship between balance and visual efficiency in elementary school aged children. $27^{\text {th }}$ Annual Neuroscience Day. April 13, 2017. Louisville, KY.

Vargas L.J., Daunis M.K., Bayers T., Bai L., Symons T.B., Caruso J.F. Comparative responses to squats done with free weights and an exoskeleton. Southeast American College of Sports Medicine. Chattanooga, Tennessee. February 17, 2018.

Mueller R.E., Bai L., O' Brien I., Vargas L.J., Schultze S.M., Garland M.R., McEnroe C., Caruso J.F. Intermittent Palm Cooling's Impact on Resistive Exercise Performance. College of Education's Spring Research Conference. March 24, 2018. Louisville, Kentucky. 
Vargas L.J., Daunis M.K., Bayers T., Bai L., Symons T.B., Caruso J.F. Comparative responses to squats done with free weights and an exoskeleton. Annual Conference of the American College of Sports Medicine. Minneapolis, Minnesota. May 31, 2018. (Accepted for Presentation).

Vargas L.J., Daunis M.K., Bayers T., Bai L., Symons T.B., Caruso J.F. Comparative responses to squats done with free weights and an exoskeleton. The $69^{\text {th }}$ International Astronautical Congress. Bremen, Germany. October 1-5, 2018. (Abstract Submitted).

\section{Peer-reviewed Science-based Articles:}

Daunis M., Bayers T., Bai L., Vargas L.J., Symons T.B., Muntis F.R., Lawson E., and Caruso J.F. (2017). Comparative responses to squats done with free weights and a robotic exoskeleton. Aerospace Medicine and Human Performance. (In Review).

Bai L., Selimovic E.A., Symons T.B., Daunis M., Bayers T., Vargas L.J., Parmar P.J., and Caruso J.F. (2017). Time course adaptations to chronic high-speed high-impact resistance exercise. 2018 ACTA Astronautica. (Pre-Selected for Publication Consideration).

Salas J., Bai L., O' Brien I., Vargas L.J., Schultze S.M., Garland M.R., McEnroe C., Caruso J.F. (2018). Performance-based correlates to vertical jump height and power values in women. Isokinetics and Exercise Science. (In Preparation).

\section{Projects:}

I. Effects of the incorporation of "Minds in Motion" training and power yoga before school hours on academic performance, perceptual, and motor skills in elementary school students attending a local Spanish-immersion school.

Research Institution: University of Louisville Status: Completed (1/17- 4/17)

\section{Community Outreach:}

I. Incorporation of Minds in Motion in a Local Spanish-Immersion Elementary School.

Funding: Cooperative Consortium for Transdisciplinary Social Justice

Research Institution: University of Louisville

Role: Graduate Research Assistant

Status: Autonomous Program 
II. Physiology Understanding Week at Floyd Knobs Elementary School. Funding: American Physiological Society Research Institution: University of Louisville Role: Graduate Research Assistant Status: Completed (1/18)

III. Floyd Knobs Elementary School Science Fair. Role: Science Fair Judge Status: Completed $(2 / 18)$ 